\title{
The Cultural Life Script as Cognitive Schema: How the Life Script Shapes Memory for Fictional Life Stories
}

\author{
Jonathan Koppel and Dorthe Berntsen \\ Center on Autobiographical Memory Research, Department of Psychology and Behavioural \\ Sciences, Aarhus University
}

This is an Accepted Manuscript of an article published by Taylor \& Francis in Memory, 22, 949971 on $17^{\text {th }}$ December 2013, available online at:

http://www.tandfonline.com/10.1080/09658211.2013.859269.

Changes resulting from the publishing process, such as peer review, editing, corrections, structural formatting, and other quality control mechanisms may not be reflected in this document. Changes may have been made to this work since it was submitted for publication. Citation: Koppel, J., \& Berntsen, D. (2014). The cultural life script as cognitive schema: How the life script shapes memory for fictional life stories. Memory, 22, 949-971. DOI: $10.1080 / 09658211.2013 .859269$ 
This is an Accepted Manuscript of an article published by Taylor \& Francis in Memory, 22, 949-971 on $17^{\text {th }}$ December 2013, available online at: http://www.tandfonline.com/10.1080/09658211.2013.859269.

\section{Author Note}

Jonathan Koppel, Center on Autobiographical Memory Research, Department of Psychology and Behavioural Sciences, Aarhus University; Dorthe Berntsen, Center on Autobiographical Memory Research, Department of Psychology and Behavioural Sciences, Aarhus University.

This work was supported by the Danish National Research Foundation under Grant DNRF93. We would like to thank Meike Bohn, Christina Duch, and Tine B. Gehrt for their assistance in running the studies reported here, Morten Hedegaard and Christina Ottsen for their help in translating the stimulus materials into Danish, and Annette Bohn and Christina Ottsen for their helpful comments on earlier draft of this paper.

Correspondence concerning this article should be addressed to: Jonathan Koppel, Center on Autobiographical Memory Research, Aarhus University, Bartholins Allé 9, Building 1340, 8000 Aarhus C, Denmark. Tel: +45 8716 5873. Fax: +45 8715 0201. Email: jkoppel@psy.au.dk. 


\begin{abstract}
We tested, across three studies, the effect of the cultural life script on memory and its phenomenological properties. We focused, in particular, on the mnemonic effects of both schema-consistency and frequency in the life script. In addition to testing recognition (in Study 1) and recall (in Studies 2 and 3), we also collected remember/know judgments for remembered events (in Studies 1 and 2) and memory for their emotional valence (in Study 2). Our primary finding was that, across all three studies, higher-frequency events were more memorable than lower-frequency events, as measured through either recognition or recall. We also attained three additional, complementary effects: First, schema-inconsistent events received remember ratings more often than schema-consistent events (in Study 2, with a trend to this effect in Study 1); second, where an event's emotional valence was inconsistent with the life script, memory for its valence was reconstructed to fit the script (in Study 2); and, third, intrusions in recall were disproportionately for life script events (in Study 3), though that was not the case in recognition (in Study 1). We conclude that the life script serves as a cognitive schema in how it shapes memory and its phenomenological properties.
\end{abstract}




\section{The Cultural Life Script as Cognitive Schema: How the Life Script}

\section{Shapes Memory for Fictional Life Stories}

The cognitive schema (i.e., a mental structure that organizes one's knowledge and assumptions about the world) represents one of the oldest and most influential concepts in cognitive psychology (see Neisser, 1976, for an overview of early work on schemata). Schemata have been found to structure cognition across a range of contexts, including, and most importantly for the present purpose, to play a role in structuring memory. Bartlett (1932) was the first investigator to bring widespread attention to the effect of schemata on recall, with his investigations demonstrating that, in recounting a Native American folk tale, English participants reconstructed the story to better fit the Western schema of a typical narrative structure (see Bergman \& Roediger, 1999, for a more recent replication of Bartlett's findings). Much of the early experimental work on the cognitive underpinnings of memory likewise examined the role of schemata (see for example, Anderson \& Pichert, 1978; Mandler \& Johnson, 1977; Sulin \& Dooling, 1974).

In the present investigation, we followed in the vein of a more recent experimental tradition on the influence of schemata on memory. The prototype for this line of research is perhaps Brewer and Treyens' (1981) investigation on room schemata and memory. There, participants' memory was tested for the contents of a graduate student's office. Brewer and Treyens found that, in both recognition and recall, there was a positive correlation between items' schema-expectancy and memory for those items. Furthermore, in the recognition data, there was a positive correlation between schema-expectancy and false recognition for items 
which had not actually been in the room. Brewer and Treyens interpret their findings for correct recognition and recall as indicating that schemata facilitate retrieval of items which are consistent with a given schema. However, in a subsequent reanalysis, Pezdek, Whetstone, Reynolds, Askari, and Dougherty (1989) reported that memory for the items with the lowest schema-expectancy tended to be better than average, suggesting that Brewer and Treyens' conclusions may have been incomplete.

As for the false recognition data, Brewer and Treyens (1981) view their results as reflecting the integration between schematic information (i.e., in this case, the room schema) and episodic information. That is, they posit that their participants drew upon both schematic and episodic information in attempting to remember the office. When both types of information were too closely integrated, so that participants were unable to distinguish between the two, this would result in schematic false alarms.

A number of other investigators have likewise carried out schema research in this tradition, by probing for the effects of schema-consistency on either correct and/or incorrect recognition and/or recall. Thus, in addition to further studies on room schemata (Lampinen, Copeland, \& Neushatz, 2001; Nemeth \& Belli, 2006; Pezdek et al., 1989), researchers have probed for the mnemonic influence of schemata for eyewitness-related material, such as crime scenes (Holst \& Pezdek, 1992; List, 1986; Smith \& Studebaker, 1996; Tuckey \& Brewer, 2003); for the behavior of instructors in a classroom (Neuschatz, Lampinen, Preston, Hawkins, \& Toglia, 2002); for common scenes such as taking one's dog to the veterinarian or going to the beach (Bower, Black, \& Turner, 1979; Graesser, Gordon, \& Sawyer, 1979; Graesser, Woll, Kowalski, \& Smith, 1980; Lampinen, Faries, Neuschatz, \& Toglia, 2000; Shapiro \& Fox, 2002; Smith \& Graesser, 1981); for stereotypes about categories of people (e.g., gender stereotypes; 
This is an Accepted Manuscript of an article published by Taylor \& Francis in Memory, 22, 949-971 on $17^{\text {th }}$ December 2013, available online at: http://www.tandfonline.com/10.1080/09658211.2013.859269.

Kleider, Goldinger, \& Knuycky, 2008; Kleider, Pezdek, Goldinger, \& Kirk, 2008; Sherman \& Bessenhof, 1999); and for household scenes (Roediger, Meade, \& Bergman, 2001).

The most typical findings to emerge from this line of research are twofold. First, contra Brewer and Treyens' (1981) initial report, though more consistent with Pezdek et al.'s (1989) reanalysis, schema-inconsistent items are generally remembered better than schema-consistent items, at least when memory is tested through recognition (e.g., Graesser et al., 1979; Lampinen et al., 2001; Neuschatz et al., 2002; Shapiro \& Fox, 2002), as has most often been the case. However, findings are more mixed with regard to recall (e.g., Graesser et al., 1980; List, 1986; Nemeth \& Belli, 2006; Pezdek et al., 1989). This mnemonic advantage of schema-inconsistent items appears to reflect the von Restorff effect, that is, that distinctiveness aids memory (Hunt, 2006; von Restorff, 1933).

Second, false recall or recognition tends to be greater for schema-consistent items, or is otherwise in the direction of rendering material more schema-consistent than was actually the case (e.g., Graesser et al., 1980; Kleider, Goldinger, et al., 2008; Kleider, Pezdek, et al., 2008; Lampinen et al., 2000; Neuschatz et al, 2002; Roediger et al., 2001; Sherman \& Bessenhof, 1999; Smith \& Studebaker, 1996; but see Nemeth \& Belli, 2006). This effect, we should note, is mirrored in a separate but related line of research, which looks at the role of script knowledge in leading to false memories. These studies find that: (1) For both autobiographical events and fictional narratives, individuals are more likely to falsely recall the occurrence of features of an event that are consistent with script knowledge of the event than features that are inconsistent with script knowledge (Elischberger, 2005; García-Bajos \& Migueles, 2003; Ornstein et al., 1998); and (2) in memory implantation studies in children, children are more vulnerable to have memories implanted for autobiographical events for which they have greater degrees of script 
This is an Accepted Manuscript of an article published by Taylor \& Francis in Memory, 22, 949-971 on $17^{\text {th }}$ December 2013, available online at: http://www.tandfonline.com/10.1080/09658211.2013.859269.

knowledge (Otgaar, Candel, Scoboria, \& Merckelbach, 2010; Otgaar, Smeets, \& Peters, 2012).

Two final points about this tradition of schema studies bear mentioning. The first is that, in addition to recall and/or recognition, some investigators have also looked at whether schemaconsistency likewise bears on remember/know judgements for recognized or recalled items (Tulving, 1985). They typically find that, just as schema-inconsistent items are remembered better than schema-consistent items, so too are they more frequently assigned remember judgements (Lampinen al., 2000; Lampinen et al., 2001; Tuckey \& Brewer, 2003). This also appears to be due to the greater distinctiveness of schema-inconsistent items. Second, retention interval is an important factor as well. Most prominently, it plays a role in false recognition and recall, with schema-consistent false alarms and intrusions increasing over longer retention intervals (Kleider, Goldinger, et al., 2008; Kleider, Pezdek, et al., 2008; Lampinen et al., 2001; Neuschatz et al., 2002). These disparate findings across varying retention intervals reflect the greater reliance on schemata over time.

In the current investigation, we aimed to establish a new cognitive schema. We did so by applying the well-established schema paradigm to a concept that has heretofore not been recognized as a type of schema: the cultural life script.

\section{The Cultural Life Script}

The cultural life script refers to culturally shared expectations of major transitional life events (Berntsen \& Rubin, 2004). Berntsen and Rubin (2004) first established the existence of a cultural life script, by asking a sample of Danish undergraduates to imagine a typical Danish infant of their own gender, and to list the seven most important events that most likely would take place in that infant's life. Though Berntsen and Rubin found considerable overlap in many 
of the events cited by participants, there was a wide range in the frequency with which individual events were cited; across the 35 life script events Berntsen and Rubin report, the number of citations (from a sample of 103 participants) ranged from 93 (having children) to four (six events, including earning one's first money and one's baptism). Participants were also asked to provide estimates concerning several characteristics of each event they listed, such as the age at which it typically occurs and its emotional valence, under the logic that expectations regarding these characteristics are also part of the life script. Since Berntsen and Rubin's initial study, subsequent researchers have collected the life scripts of several other cultures, including Germany (Habermas, 2007), Turkey (Erdoğan, Baran, Avlar, Taş, \& Tekcan, 2008), the United States (Rubin, Berntsen, \& Hutson, 2009), and the Netherlands (Janssen \& Rubin, 2011).

Part of Berntsen and Rubin's (2004) interest in the life script stems from their claim that it structures recall from autobiographical memory. To date, support for this claim lies primarily in evidence suggesting that the life script may partially underlie the reminiscence bump in autobiographical memory (i.e., the greater accessibility in recall of autobiographical events occurring in adolescence and early adulthood, roughly, from 15 to 30 years of age; Rubin \& Schulkind, 1997). For instance, Berntsen and Rubin found that the age distribution of life script events features a bump between the ages of 15 and 30 as well. Furthermore, Rubin and Berntsen (2003) found that exceptions to the bump in autobiographical memory tracked with exceptions to the bump in the life script: Just as they found a bump, in a Danish sample, in the age distribution of memories for positive events (e.g., when people reported being most proud or most in love) but not negative events (e.g., when people reported being angriest or most sad), so too did they find a bump in cultural expectations for when a hypothetical 70-year-old would have 
experienced the same positive events, but not the same negative events (for similar findings in a Malaysian sample, see Haque \& Hasking, 2010).

These findings suggest that the life script structures recall of emotional and important life events by rendering events that fall within it highly accessible. However, existing research testifying to that effect is, almost exclusively, correlational in nature: it demonstrates merely that the reminiscence bump in autobiographical memory tracks with the life script. There has, then, been little laboratory research directly demonstrating that the life script influences memory, as would be true of a cognitive schema (but see Coleman \& Belli, 2009). The present investigation was intended to address this gap.

The cultural life script as cognitive schema. There are two dimensions by which life script events can be classified according to their fidelity to the script. The first dimension is an event's consistency with its expected characteristics according to the script, such as those characteristics cited above (i.e., the age at which it occurs and its emotional valence). The second dimension is an event's frequency in the life script, that is, how often it is cited as a life script event. Here, we probed for the influence of both of these dimensions on memory and its phenomenological properties.

Two points about the latter dimension, namely, an event's frequency in the life script, require further explication. First, event frequency is conceptually distinct from schemaconsistency, in that events which are less frequently cited as part of the life script are not violations of the script, in the same way that schema-inconsistent events represent script violations; low-frequency events are merely not considered to be a life script event by as many people as are high-frequency events. Second, event frequency is likewise distinct from the 
prevalence with which an event occurs in the lifespan of individuals within a given culture. That is, inasmuch as the life script represents an idealized life, and is primarily comprised of transitional events within a given culture, the citation of an event as a life script event should not be determined by the event's prevalence. This was borne out by Berntsen and Rubin (2004), who, among the ratings they collected for each cited event, asked participants to estimate how

many people, out of 100, would experience the event at least once in their lives. They found no association between these prevalence ratings and the frequency with which an event was included in the life script. These prevalence ratings can additionally be seen as ratings of the general plausibility of each event, given that, as Pezdek, Blandon-Gitlin, Lam, Hart, and Schooler (2006) note, the operational definition of an implausible event in the memory construction literature is typically "one that is perceived as having a low probability of occurrence for individuals in the cohort tested" (p. 1628).

\section{Overview of the Current Studies}

In the current investigation, we present three studies in which we applied the schema paradigm to the cultural life script. Each of these studies followed a similar methodology. First, participants read a fictional life story, containing a number of events varying in both their consistency with the life script and their frequency in the script. Then, after a retention interval of varying duration, memory for the story was assessed through either a recognition or recall task. At the same time, remember/know judgements, and/or assessments of recall for relevant characteristics of each remembered event (e.g., its emotional valence), were taken as well. With each study, we offer specific predictions concerning the expected results. For now, it will suffice to say that we hypothesized that the cultural life script would function as a type of cognitive 
schema.

\section{Study 1}

The method we employed in Study 1 followed the parameters described above. Participants read a fictional life story, then later completed a recognition task assessing their memory for the story, with remember/know judgements collected as part of the recognition task. We assessed memory through a recognition task, rather than a recall task, in order to proceed as closely as possible from the bulk of the prior schema research, and also because it allowed us to specifically probe for whether false memories would disproportionately incorporate life script events. We varied the retention interval as well, employing retention intervals of 20 minutes and one week, to test whether the mnemonic influence of the life script schema increased over time.

Based on prior research, and our own suppositions as to how the life script would serve to structure memory and its phenomenological properties, we began with the following four hypotheses: (1) In light of the von Restorff effects that have been found with schemainconsistent material in prior schema research, particularly when memory has been tested through recognition (e.g., Graesser et al., 1979; Lampinen et al., 2001; Neuschatz et al., 2002; Shapiro \& Fox, 2002), we hypothesized that correct recognition would be greater for schemainconsistent than schema-consistent events; (2) following from Berntsen and Rubin's (2004) contention that life script events are rendered more memorable than non-life-script events, we hypothesized that, given that high-frequency events are considered to be a life script event by more people than are low-frequency events, correct recognition would correspondingly be greater for high-frequency events; (3) based on the distinctiveness effects on remember/know judgements in prior schema research, in which schema-inconsistent items have received more remember judgements (e.g., Lampinen et al., 2000; Lampinen et al., 2001; Tuckey \& Brewer, 
2003), we hypothesized that the same would hold true here; and (4) based on the prior findings of greater false recognition and recall for schema-consistent than inconsistent material (e.g., Kleider, Goldinger, et al., 2008; Neushatz et al., 2002; Roediger et al., 2001), we likewise hypothesized that false recognition would be greater for life script events than for non-life-script events. That is, given that life script events are attached to the life script, while non-life-script events are not attached to the script, non-life-script events should not be the object of schematic false alarms to the same extent as life script events.

Lastly, inasmuch as the mnemonic effects of schemata tend to increase over time (Kleider, Goldinger, et al., 2008; Kleider, Pezdek, et al., 2008; Lampinen et al., 2001; Neuschatz et al., 2002), we expected these effects to generally either be more pronounced in the longer of the two retention intervals (which, again, were 20 minutes and one week, respectively), or to emerge only at the longer retention interval.

\section{Method}

Participants. We recruited 48 Aarhus University students. We utilized exclusively female participants in each of the three studies reported here. This is because our theoretical rationale presumes that the life script of our sample matched the Danish life script reported in Berntsen and Rubin (2004), which was based on a primarily female sample. The sample's mean age was age 22.80 years (range $=19-31$ years). Participants received two cinema tickets as compensation. 
This is an Accepted Manuscript of an article published by Taylor \& Francis in Memory, 22, 949-971 on $17^{\text {th }}$

December 2013, available online at: http://www.tandfonline.com/10.1080/09658211.2013.859269.

\section{Materials}

Fictional life story. The source material consisted of a fictional story about a woman's

life. We chose to make the story's protagonist a woman, rather than a man, for reasons similar to those underlying our recruiting exclusively female participants: The life script that participants considered to be operative for the protagonist should have likewise mirrored, as closely as possible, the original Danish life script of Berntsen and Rubin (2004). The story included nine critical events, which are illustrated in Table 1.

Two-thirds (six) of the critical events were schema-consistent, and one-third (three) were schema-inconsistent. Schema-consistency was manipulated by manipulating events' emotional valence. That is, schema-consistent events had the same emotional valence as would be expected based on the life script, as measured by the ratings of emotional valence that Berntsen and Rubin (2004) collected from participants for each life script event they cited. Schemainconsistent events, for their part, had the opposite emotional valence as would be expected based on the life script; events that are positive according to the script (e.g., marriage) were presented as negative events in the life of the protagonist, while typically negative events (e.g., divorce) were presented as being positive. We chose to manipulate emotional valence because the life script is thought to represent an idealized version of life, which is inevitably positively biased, for which reason emotional valence is central to the script (Berntsen \& Rubin, 2004).

It is worth noting that this manipulation of schema-consistency differed from those typically employed in prior schema studies. That is, researchers probing for the effects of schema-consistency generally insert schema-inconsistent items into their source material (e.g., in Brewer \& Treyens, 1981, the placement of a tennis racket in a graduate student's office). In our case, however, the items themselves - the life script events we employed - were identical across 
the schema-consistent and schema-inconsistent categories. The experimental manipulation concerned, instead, one of the characteristics of the relevant events, that is, their emotional valence. We nonetheless believe, however, that the schema-inconsistent events in the story can comfortably be classified as such, inasmuch as they represent violations of the life script; it is just that the violation of the life script centers around a salient characteristic of the events, rather than the occurrence of the events in and of themselves.

Life script events were selected to serve as critical events according to three criteria: (1) Each event had to be rated as either strongly positive or strongly negative in Berntsen and Rubin (2004), to allow for its emotional valence to be reversed; (2) the schema-consistency manipulation had to be successful for each event, in that participants would consider the schemainconsistent version of each event to be atypical, which we tested by asking a pilot sample of 14 Danish university students to rate the typicality of the schema-consistent and inconsistent versions of each event; and (3) we aimed to have as balanced a combination of positive and negative life script events as possible. These criteria did limit the number of critical events we could include in the story, and, thus, for which we could test in the subsequent recognition task. However, it would have been counterproductive to include, as critical items, events which were inappropriate to the manipulation or whose typicality could not be successfully manipulated through reversing their emotional valence.

In order to counterbalance assignment of each event as either schema-consistent or schema-inconsistent, we constructed three versions of the story, rotating which events fell into the schema-inconsistent category. Across these three story versions, we maintained a consistent distribution of positive and negative events across the schema-consistent and schemainconsistent categories; in each case, two-thirds of both the schema-consistent and schema- 
This is an Accepted Manuscript of an article published by Taylor \& Francis in Memory, 22, 949-971 on $17^{\text {th }}$ December 2013, available online at: http://www.tandfonline.com/10.1080/09658211.2013.859269.

inconsistent events were positive, and one-third were negative. Each participant read one of these three story versions.

Additionally, and as likewise illustrated in Table 1, we classified the three events cited most often as a life script event in Berntsen and Rubin (2004) as high-frequency events, and the six other events as low-frequency events. Because we could not manipulate event frequency, it is important that we rule out, as much as possible, alternative explanations for any mnemonic effects of event frequency. Towards that end, two such potential confounds are the perceived prevalence and emotional valence of each event. However, we can rule out perceived prevalence as a confound, because the high- and low-frequency events were comparable in terms of the estimated prevalence ratings reported by Berntsen and Rubin, in which, as noted in the Introduction, participants were asked how many people (out of 100) would experience the event at least once in their lives $\left(M_{\text {High Frequency }}=81.79\right.$ people; $M_{\text {Low Frequency }}=81.18$ people $)$. These prevalence ratings also serve to rule out general plausibility as a confound, given the strong link between perceived prevalence and perceived plausibility we noted in the Introduction (Pezdek, Blandon-Gitlin, Lam, et al., 2006).

The high- and low-frequency events did differ in the ratings of their emotional valence collected by Berntsen and Rubin (2004). However, given the schema-consistency manipulation, this did not present a critical concern, since events would not always be presented according to their typical emotional valence. Lastly, in the interest of creating a reasonable life story narrative, we included a number of filler events, incorporating both life script and non-life-script events. In total, the three versions of the story ranged from 1097 words to 1147 words. In the Appendix, we provide the English translation of one of the story versions. 
This is an Accepted Manuscript of an article published by Taylor \& Francis in Memory, 22, 949-971 on $17^{\text {th }}$ December 2013, available online at: http://www.tandfonline.com/10.1080/09658211.2013.859269.

Recognition task. The recognition task consisted of a series of yes/no questions (e.g., In the story you read, did the main character get married?). Besides querying participants about the nine critical items from the story, the recognition task also included 18 foils, half of which (9) queried participants about life script events, and half of which (9) queried them about nonlife-script events. The non-life-script foils were selected among non-life-script events, which, in a pilot sample of 11 Danish university students, were rated as being roughly as prevalent as the life script foils; in fact, the non-life script foils were rated as slightly more prevalent: When asked [following Berntsen \& Rubin's (2004) procedure] to rate how many people, out of 100, would experience each event at least once in their lives, the pilot sample assigned a mean rating of 85.42 people to the life script foils, compared to 86.68 people for the non-life-script foils. As examples of the foils, one asked participants whether the protagonist had gotten a driver's license in the story, and another asked whether she had an $18^{\text {th }}$ birthday party.

For each item that participants recognized, they were also asked to judge whether they remembered or knew that it had occurred in the story. At the beginning of the recognition task, participants were instructed, following a Danish translation of Rajaram's (1993) remember/know instructions, on how to make the remember/know judgements.

Procedure. The study took place over three phases: (1) a reading phase, (2) a delay, and (3) a testing phase, wherein participants completed the recognition task. In the reading phase, participants read the story on a computer screen. Each event took the form of a single paragraph, which was presented on the screen for an ample 40 seconds. In between each event, participants were asked, as manipulation checks, to rate the emotional valence and typicality of the preceding 
event. These ratings were on a 1-7 scale (for emotional valence, $1=$ very negative, $7=$ very positive; for typicality, $1=$ very atypical, $7=$ very typical .

In the delay, participants were divided into two conditions. In the 20-minute condition, participants played Sudoku as a distractor task for 20 minutes, before proceeding to the testing phase. In the one-week condition, participants were simply dismissed after reading the story, and returned a week later for the testing phase. Lastly, in the testing phase, participants completed the recognition task, including the remember/know judgements.

Design. In total, the study's design incorporated one between-subjects variable (retention interval - 20-minute condition vs. one-week condition) and three within-subjects variables (schema-consistent vs. inconsistent events, high-frequency vs. low-frequency events, and, among the foils, life script foils vs. non-life-script foils).

\section{Results and Discussion}

In the following, we divide the results into four sections. These sections concern, respectively: (1) the manipulation checks, (2) correct recognition of events from the story, (3) remember/know judgements of correctly recognized events, and (4) false recognition of events that were not included in the story. Where appropriate, we divide our analyses into those concerning the comparison of schema-consistent versus inconsistent events on the one hand, and high-frequency versus low-frequency events on the other.

Manipulation checks. For the schema-consistency manipulation to be successful, participants would need to rate positive events as less positive when they were putatively 
schema-inconsistent, relative to when the same events were putatively schema-consistent.

Similarly, participants would need to rate negative events as less negative when they were putatively schema-inconsistent, compared to when they were putatively schema-consistent.

Moreover, participants would need to rate both positive and negative events as less typical when they were schema-inconsistent.

All of these conditions were met. Collapsed across the 20-minute and one-week conditions, positive events were rated as significantly less positive on the 1-7 Likert scale when they were schema-inconsistent $\left[M_{\text {Schema-Inconsistent Events }}=2.18(S D=.87)\right.$ to $M_{\text {Schema-Consistent Events }}=$ $6.39(S D=.64) ; t(47)=-26.14, p<.001, d=3.77]$; negative events were rated as significantly less negative when they were schema-inconsistent $\left[M_{\text {Schema-Inconsistent Events }}=5.40(S D=.64)\right.$ to $\left.M_{\text {Schema-Consistent Events }}=1.58(S D=.65) ; t(47)=21.75, p<.001, d=3.14\right]$; and, taking both positive and negative events together, events were rated as significantly less typical when they were schema-inconsistent $\left[M_{\text {Schema-Inconsistent Events }}=3.18(S D=.63)\right.$ to $M_{\text {Schema-Consistent Events }}=5.21$ $(S D=.67) ; t(47)=-15.91, p<.001, d=2.30]$.

Correct recognition. The proportions of recognized events from the story are illustrated in Figure 1a. There was no significant difference in levels of correct recognition across the three versions of the story $\left[M_{\text {Story Version \#1 }}=.97(S D=.05), M_{\text {Story Version \#2 }}=.97(S D=.06)\right.$, and $M_{\text {Story }}$ Version $\# 3=.94(S D=.09) ; F(2,45)=.83 \cdot p=.44]$.

We turn next to a comparison of participants' recognition for schema-consistent versus inconsistent events, and high-frequency versus low-frequency events. ${ }^{1}$

\footnotetext{
${ }^{1}$ Though schema-consistency (schema-consistent vs. schema-inconsistent events) and event frequency (high-frequency vs. low-frequency events) were crossed within-subjects, we were unable to test for an interaction between the two variables: Once the nine critical events in the three versions of the story are distributed across
} 
Schema-consistent versus schema- inconsistent events. In an ANOVA with retention interval as a between-subjects factor (20 minute-condition vs. one-week condition), and schemaconsistency as a within-subjects factor (schema-consistent vs. schema-inconsistent events), we found a main effect of retention interval, as recognition was lower in the one-week condition than the 20-minute condition, $F(1,46)=10.93, p=.002, n_{p}{ }^{2}=.19$. There was no main effect of schema-consistency, $F(1,46)=.05, p=.83$, nor an interaction between schema-consistency and retention interval, $F(1,46)=.81, p=.37$. Therefore, though correct recognition decreased over the retention interval, we did not find that schema-consistency had any bearing on rates of correct recognition.

High-frequency versus low-frequency events. In an ANOVA with retention interval as a between-subjects factor, and frequency in the life script as a within-subjects factor (highfrequency vs. low-frequency events), we found an interaction between retention interval and frequency in the life script, $F(1,46)=13.05, p=.001, n_{p}{ }^{2}=.22$, as recognition for lowfrequency events decreased significantly more from the 20-minute condition to the one-week condition than did recognition for high-frequency events. As Figure 1a suggests, in follow-up paired-samples $t$-tests comparing recognition for high-frequency versus low-frequency events separately in the 20-minute and one-week conditions, we found no significant difference in the 20 -minute condition, $t(23)=1.00, p=.33$, but did find a significant difference in the one-week condition, $t(23)=4.01, p=.001, d=.82$. In sum, high-frequency events were correctly

the four event categories which are yielded by crossing these variables (high-frequency/schema-consistent events, high-frequency/schema-inconsistent events, low-frequency/schema-consistent events, and lowfrequency/schema-inconsistent events), there are several instances, across the three story versions, in which a given category contains no events or only one event. Consequently, there is too much missing data (in the case of cells containing no events) or unreliable data (in the case of cells containing only one event) to produce a meaningful analysis. Therefore, in all analyses concerning the effects of either event frequency or schemaconsistency, we confined ourselves to testing for main effects of each variable. 
recognized at higher proportions than low-frequency events. This difference was not evident at the 20-minute retention interval, but emerged at one week, as recognition declined for lowfrequency events but remained stable for high-frequency events.

Remember/know judgements for correctly recognized events. The proportions of remember judgements assigned to correctly recognized events are illustrated in Figure $1 b$.

Schema-consistent versus schema-inconsistent events. In an ANOVA with retention interval as a between-subjects factor and schema-consistency as a within-subjects factor (schema-consistent vs. schema-inconsistent events), we found no main effect of retention interval, $F(1,46)=1.39, p=.24$, indicating that the proportion of remember judgements did not decline significantly across the two retention intervals. There was a trend towards a main effect of schema-consistency, $F(1,46)=3.30, p=.076, n_{p}{ }^{2}=.07$, reflecting a trend towards a significantly higher proportion of remember judgments for schema-inconsistent events. There was no interaction between retention interval and schema-consistency, $F(1,46)=2.67, p=.11$, indicating that the difference in remember judgments for schema-inconsistent versus schemaconsistent events did not vary significantly as a function of retention interval.

High-frequency versus low-frequency events. In an ANOVA with retention interval as a between-subjects factor and frequency in the life script as a within-subjects factor (highfrequency vs. low-frequency events), we found no main effect of retention interval, $F(1,46)=$ $2.32, p=.13$, indicating that, here as well, the proportion of remember judgements did not decline significantly from 20 minutes to one week. There was no main effect of frequency in the life script, $F(1,46)=.26, p=.61$, nor an interaction between retention interval and frequency in the life script, $F(1,46)=.29, p=.59$. Taken together, then, we found no relation between 
frequency in the life script and the proportion of remember judgements assigned to correctly recognized events.

False recognition. In an ANOVA with retention interval as a between-subjects factor, and scriptedness of the foils in the recognition task as a within-subjects factor (life script foil vs. non-life-script foil), we found a main effect of retention interval $\left[M_{20}\right.$ Minutes $=.04(S D=.07)$ to $\left.M_{\text {One-Week }}=.11(S D=.11) ; F(1,46)=-10.57, p=.002, n_{p}{ }^{2}=.19\right]$, indicating that the proportion of falsely recognized events was greater at one week than at 20 minutes. However, there was neither a main effect of scriptedness of the foils [ $M_{\text {Life Script Foils }}=.08(S D=.11)$ to $M_{\text {Non-Life-Script }}$ Foils $=.07(S D=.09) ; F(1,46)=.57, p=.46]$, nor an interaction between retention interval and foil scriptedness, $F(1,46)=.06, p=.81$. All told, though false recognition increased from 20 minutes to one week, participants were not any more prone to falsely recognize life script events, compared to non-life-script events.

Discussion. In Study 1, we found that the cultural life script structured memory for a fictional life story in two discrete respects. First, Hypothesis \#2 was borne out: high-frequency events were correctly recognized more often than low-frequency events. The greater correct recognition for high-frequency events was concentrated in the longer retention interval. Therefore, consistent with prior research on other schemata (e.g., Kleider, Pezdek, et al., 2008; Lampinen et al., 2001; Smith \& Graesser, 1981), the life script schema played a more substantial role in shaping memory as the length of the retention interval increased. Second, though our findings in support of Hypothesis \#3, regarding remember/know judgements for correctly 
recognized events, were less strong, we did find a trend for schema-inconsistent events to be given remember judgements more frequently than schema-consistent events.

Of the remaining two hypotheses, schema-inconsistent events were not correctly recognized at greater rates than schema-consistent events (as predicted in Hypothesis \#1), nor was false recognition greater for life script foils than for non-life-script foils (as predicted in Hypothesis \#4). We reasoned that our failure to find either effect may have had to do with ceiling effects (in the former case) and floor effects (in the latter case): As the means in Figure 1a indicate, correct recognition was sub-optimally high, and false recognition was likewise suboptimally low. This suggests that the task demands placed upon participants in Study 1 may have been too easy for the predicted effects to emerge.

In Study 2, therefore, we set out to create a more challenging task for our participants. Additionally, given the relatively small number of critical events we were able to include in the story, it was desirable to test whether the predicted effects we did attain would hold in a followup study.

\section{Study 2}

In Study 2, we endeavored to fashion more cognitively demanding conditions for the participants. We did so by presenting them with less favorable encoding conditions, and by testing their memory through recall, rather than recognition. The former aim was achieved in two ways. First, whereas in Study 1 we controlled the pace at which participants read the story, and provided more than sufficient time to do so, in Study 2 we allowed participants to read the story at their own pace; we expected that, under these circumstances, participants would spend considerably less time reading it. Second, we no longer asked participants to rate the emotional 
valence and typicality of each event as they read the story, under the logic that this, too, may have deepened encoding of the story in Study 1.

The primary goals of Study 2, then, were twofold: (1) To extend those significant results we did obtain in Study 1 to recall, and (2) to test whether the predicted effects which we did not obtain in Study 1 would emerge under more demanding conditions.

Two other respects in which the materials and procedure of Study 2 differed from those of Study 1 warrant preliminary note. First, given that, in Study 1, there was some indication that the effect of the life script schema was stronger in the one-week condition, we employed only a one-week condition here. Second, as part of the recall task, we also asked participants to recall the emotional valence of each recalled event. In doing so, we were interested in whether memory for the emotional valence of schema-inconsistent events (i.e., events which had been presented with the opposite valence as would be expected based on the life script) would be reconstructed to render their valence more consistent with the life script.

Following from Study 1 and the dictates of schema theory, we began with five hypotheses. The first four were essentially the same hypotheses we outlined for Study 1, only applied here to recall: (1) The proportion of events recalled would be greater for schemainconsistent than schema-consistent events; (2) the proportion of events recalled would be greater for high-frequency than for low-frequency events; (3) schema-inconsistent events would be given remember judgements more often than schema-consistent events; and (4) any intrusions we found would disproportionately reflect the influence of the life script. Hypothesis \#5 concerned the addition of the ratings of recalled emotional valence. Specifically, for schemainconsistent events, we predicted that memory for their valence would be reconstructed to render it more consistent with the script. For instance, when typically positive events (e.g., marriage) 
were rendered as negative in the story, we expected that, with recall for emotional valence governed in part by the life script schema, participants would remember them as being more positive than they actually were.

\section{Method}

Participants. Twenty-four female participants were recruited from the student body of Aarhus University. They had a mean age of 23.65 years (range $=20-38$ years). Participants received two cinema tickets as compensation.

\section{Materials.}

Fictional life story. As source material, we used the same fictional story employed in Study 1. Again, as illustrated in Table 1, there were nine critical events in the story, taken from Berntsen and Rubin's (2004) Danish life script. Two-thirds (six) of the events were schemaconsistent, and one-third (three) were schema-inconsistent, with schema-consistency again manipulated by manipulating events' emotional valence. Schema-consistency was again counterbalanced across the three versions of the story, rotating which critical events served as schema-inconsistent events. Each participant read one of these three versions. Lastly, we again classified the three most-cited events in the life script as high-frequency events, and the six other events as low-frequency events.

Recall task. The recall task was administered on a computer screen. In order to allow for remember/know judgements and ratings of recalled emotional valence to be applied to each recalled event, we employed a structured recall task: Participants were instructed, initially, to recall the first specific event from the story that they could remember. They were advised that a 
specific event referred to a single, discrete event from the story, occurring at a particular time and place. For this recalled event, they were then asked to make a remember/know judgement concerning it, and to rate the emotional valence they recalled having been attached to it. The ratings of emotional valence took place on a Likert scale of 1 to $7(1=$ very negative, $7=$ very positive). As in Study 1, participants had been instructed on how to make remember/know judgements at the beginning of the recall task, following a Danish translation of Rajaram's (1993) remember/know instructions.

After recalling the first event and supplying the remember/know judgements and ratings of recalled emotional valence, participants were asked to recall the second event they could think of, and to supply the same remember/know judgements and ratings of recalled emotional valence for this event as well. This process was repeated until participants indicated that they could not recall any more events.

Procedure. As in Study 1, the study took place over three phases: (1) a reading phase, (2) a delay, and (3) a testing phase, wherein participants completed the recall task. In the reading phase, participants read the story on a computer screen. As in Study 1, each event from the story was presented as a single paragraph. As noted above, we changed two aspects of the reading phase procedure of Study 1. That is, we now allowed participants to set their own pace through the story - they were instructed to simply continue in the story once they had completed a paragraph - and we no longer asked participants to rate the emotional valence and typicality of each event as they read it. After reading the story, participants returned a week later for the testing phase, at which point they completed the recall task. 
Coding of the recall task. Coding of the recall task focused on two elements: (1) the proportion of correctly recalled events, and (2) the number of intrusions. Events from the story were coded as having been recalled if they were referred to on a gist level. In coding for intrusions, we coded as intrusions any recollections that did not appear to be derived from the actual events of the story. Fifty percent of the recall tasks were dual-coded by two independent raters. We assessed the reliability of each measure through the calculation of either kappas or Pearson correlations, whichever was appropriate to the measure. Reliability was good, with these ratings exceeding .80 in both cases. The remaining recall tasks were coded by one rater.

Though coding was straightforward in most respects, the nature of the recall task presented one complication: There were occasional instances in which participants' segmentation of events did not match ours, in that two or more events were described as one event (e.g., the protagonist's getting married and having children were described as one event). Where this occurred, we only applied the ensuing remember/know judgements and ratings of emotional valence (which, again, were collected after each recalled "event") towards the immediately preceding event (e.g., if the participant cited two events, the rating was applied only to the second event). We coded the recall task in this way because it was apparent, particularly in the ratings of emotional valence, that these ratings were addressing the most recently cited event (e.g., if the protagonist's marriage and divorce were mentioned together, the ensuing emotion rating tended to be negative).

Design. The study took the form of a 2 x 2 design, with both independent variables being within-subjects subjects (schema-consistent vs. inconsistent events, and high-frequency vs. lowfrequency events). Lastly, though the study's design did not specifically probe for whether 
instances of false recall would reflect the life script, the recall tasks could be plumbed for this effect. We were interested, therefore, in pursuing this analysis as well.

\section{Results and Discussion}

In the following, we divide our results along four sets of discrete analyses, concerning, respectively: (1) correct recall, (2) remember/know judgements, (3) intrusions, and (4) recalled emotional valence. As in Study 1, where appropriate, we subdivide the following analyses into those concerning, first, the comparison between schema-consistent and schema-inconsistent events, and, second, the comparison between high-frequency and low-frequency events.

Correct recall. We calculated, for each participant, the proportion of critical events from each event category which were recalled. For instance, if a participant recalled four of the six schema-consistent events, she received a .67 for that category. Descriptive statistics for the proportions of events recalled are reported in Table 2. Here, there was a significant difference in levels of recall across the three story versions $\left[M_{\text {Story Version \#1 }}=.85(S D=.14), M_{\text {Story Version \#2 }}=\right.$ $.68(S D=.13)$, and $\left.M_{\text {Story Version \#3 }}=.67(S D=.18) ; F(2,21)=3.55 . p=.047\right]$. The proportion of filler events recalled - collapsed across both life script and non-life-script filler events - was .41 $(S D=.24)$.

To get a sense of the retrieval strategies employed by participants, we also calculated, individually for each participant, the Spearman rank correlation between the order in which events were recalled and the order in which they appeared in the story. In doing so, we collapsed across both critical and filler events. These analyses indicated that participants largely recalled events in the order in which they appeared in the story: Across all participants, the mean 
correlation coefficient was $.85(S D=.28)$, which was significantly greater than a correlation coefficient of 0 , as indicated in a one-sample $t$-test, $t(23)=14.69, p<.001, d=3.00$.

We turn next to a comparison of recall for schema-consistent versus inconsistent events, and high-frequency versus low-frequency events. ${ }^{2}$

Schema-consistent versus inconsistent events. As Table 2 indicates, in a pairedsamples $t$-test comparing the proportion of schema-consistent versus schema-inconsistent events recalled, we found no significant difference in the proportions of events recalled, $p=.54$.

High-frequency versus low-frequency events. As Table 2 indicates, we found a trend towards a significant difference in the proportions of high-frequency versus low-frequency events recalled, $p=.075, d=.38$, as high-frequency events were recalled at higher rates than low-frequency events.

Remember/know judgements. Descriptive statistics for the proportions of remember judgements assigned to recalled events are reported in Table 2. Because remember/know judgements could only be collected for recalled events, we were concerned that, for individual participants, mean remember/know scores would be unreliable in event categories (e.g., schemaconsistent events) where participants recalled few events. Therefore, for each event category, we computed mean scores for the proportion of events assigned remember judgements only for participants from whom we had a remember/know judgement for more than one event..

Schema-consistent versus inconsistent events. As Table 2 indicates, in a paired-samples $t$-test comparing the proportion of remember judgements assigned to schema-consistent versus

\footnotetext{
${ }^{2}$ As in Study 1, we were unable to test for an interaction between schema-consistency and event frequency for any of the relevant analyses. Consequently, we again confined ourselves to testing for main effects of each variable.
} 
schema-inconsistent events, we found a significant difference between them, $p=.025, d=.56$, as schema-inconsistent events received a significantly greater proportion of remember judgements than did schema-consistent events.

High-frequency versus low-frequency events. As Table 2 indicates, we found no significant difference in the proportion of remember judgements assigned to high-frequency versus low-frequency events, $p=.27$.

Intrusions. We found only minimal intrusions in participants' recollections. Therefore, though we had hypothesized that intrusions would disproportionately reflect the life script, this analysis was rendered moot.

Recalled emotional valence. We used the ratings of emotional valence for each event that we collected in Study 1 (which, again, participants assigned as they read the story) as a reference point against which to compare the ratings of recalled emotional valence in Study 2. In effect, the ratings from Study 1 served as norms, with the point of interest in the present analyses being whether, and in what direction, the memorial ratings deviated from these norms.

Figure 2 illustrates the comparison between the norms from Study 1 and the memorial ratings from Study 2. For both the norms and memorial ratings, we collapsed the ratings across individual events to arrive at separate mean ratings for positive schema-consistent events, positive schema-inconsistent events, negative schema-consistent events, and negative schemainconsistent events. The figure reveals a pattern that matches our prediction quite well. For both positive and negative events, when events were schema-consistent, the recall ratings were slightly more conservative than the norms - recall ratings of the emotional valence of positive 
schema-consistent events were less positive than the norm ratings, while the ratings for negative schema-consistent events were less negative than the norms. We tested for the significance of these differences in one-sample $t$-tests between the recall ratings and the norms, treating the norm ratings as test values. These $t$-tests yielded significant results in both cases: for positive schema-consistent events, $t(21)=-3.69, p=.001, d=.79$; for negative schema-consistent events, $t(23)=2.09, p=.048, d=.43$.

However, for schema-inconsistent events, the recall ratings differed from the norms in the opposite direction. That is, recall ratings for positive schema-inconsistent events were more positive than the norm ratings, $t(19)=3.83, p=.001, d=.86$, while recall ratings for negative schema-inconsistent events were more negative than the norms, $t(17)=-5.33, p<.001, d=1.29$. For both positive and negative schema-inconsistent events, therefore, the recall ratings differed from the norms in a direction that rendered events' emotional valence as more consistent with the valence that would be expected based on the life script.

Discussion. In Study 2, we replicated the results of Study 1, using recall rather than recognition, and under less favorable encoding conditions. That is, as predicted above, in Hypotheses \#2 and \#3, respectively, recall tended to be better for high-frequency events than for low-frequency events (although this effect only reached a trend), and schema-inconsistent events received remember judgements more frequently than did schema-consistent events.

Furthermore, the chief null findings of Study 1 remained null findings here as well; as in the recognition data from Study 1, we did not find a significant difference (as we had predicted would be the case in Hypothesis \#1, above) in levels of recall for schema-consistent versus schema-inconsistent events, nor did we find a significant difference in the proportion of 
This is an Accepted Manuscript of an article published by Taylor \& Francis in Memory, 22, 949-971 on $17^{\text {th }}$ December 2013, available online at: http://www.tandfonline.com/10.1080/09658211.2013.859269.

remember judgements assigned to high-frequency versus low-frequency events. The former result is particularly noteworthy, indicating as it does that our failure, in Study 1, to find a significant difference in correct recognition between schema-consistent versus schemainconsistent events was not due to ceiling effects, as we had posited might have been the case.

Taken together, Studies 1 and 2 paint a consistent picture that schema-consistency affects remember/know judgements, while greater frequency of an event in the life script is associated with better recognition or recall for that event. Lastly, we also found that memory for emotional valence was reconstructed according to the life script schema (as predicted in Hypothesis \#5). However, the paucity of intrusions in participants' recall meant that we could not investigate Hypothesis \#4, that intrusions would likewise reflect the influence of the life script.

As consistent as the pattern of results were across Studies 1 and 2, we suspected that the constraints of the schema-consistency manipulation were precluding an optimal test of the association between frequency in the life script and recall. That is, the limitation of only being able to use events for which the schema-consistency manipulation was feasible may have undermined our test of the effects of frequency in the life script in two ways. Specifically, the relatively few critical events we were able to use in both the high-frequency and low-frequency categories created the possibilities that (1) these events were not necessarily representative of their respective categories, and/or (2) these events may have been rendered fairly easy to remember, and consequently left participants relatively non-reliant on the life script in recalling them. This would have obscured the true difference in mnemonic accessibility of high-frequency versus low-frequency events. Additionally, the small number of events in the story may have obviated the possibility of attaining a more meaningful number of intrusions. In Study 3 , therefore, we set out to address these limitations of Studies 1 and 2. 
This is an Accepted Manuscript of an article published by Taylor \& Francis in Memory, 22, 949-971 on $17^{\text {th }}$

December 2013, available online at: http://www.tandfonline.com/10.1080/09658211.2013.859269.

\section{Study 3}

In Study 3, we focused on the effects of frequency in the life script by discarding the schema-consistency manipulation. As noted above, this enabled us to more effectively test the effects of event frequency, in that it provided the opportunity to include a greater number of critical events in the story. In addition to high-frequency life script events and low-frequency life script events, we also included non-life-script events, in order to compare recall for non-lifescript events to recall for both categories of life script events; just as low-frequency life script events are not considered to be a life script event by as many people as are high-frequency events, non-life-script events are considered to be life script events by even fewer individuals (nor, however, do they represent violations of the script, inasmuch as the occurrence of these events over the course of someone's life would not violate cultural expectations regarding the events that are expected to take place over the lifespan of a typical individual within that culture). On a final preliminary note, we did not collect remember/know judgements in Study 3, as there had been no evidence, in either Study 1 or Study 2, of an association between frequency in the life script and the proportion of events assigned remember judgements.

Following from the first two studies, and the implications of our logic as to how the life script should structure recall, we began with the following two hypotheses: (1) High-frequency life script events would be recalled most frequently, followed by low-frequency life script events, followed by non-life-script events; and (2) any intrusions we found would disproportionately reflect the influence of the life script. 
This is an Accepted Manuscript of an article published by Taylor \& Francis in Memory, 22, 949-971 on $17^{\text {th }}$

December 2013, available online at: http://www.tandfonline.com/10.1080/09658211.2013.859269.

\section{Method}

Participants. Thirty female participants were recruited from the student body of Aarhus University. They had a mean age of 22.76 years (range $=20-27$ years). Participants received two cinema tickets as compensation.

\section{Materials.}

Fictional life story. The source material consisted of an expanded version of the fictional life story employed in Studies 1 and 2. As illustrated in Table 3, this version of the story included thirty critical events. As the table indicates, based on the number of citations in the Danish life script (Berntsen \& Rubin, 2004), we classified one-third of these events as highfrequency life script events, one-third as low-frequency life script events, and one-third as nonlife-script events. There were also several filler events. Overall, the story was 1445 words long. Without the schema-consistency manipulation, we only needed to employ one version of the story, rather than the three versions of Studies 1 and 2.

As in Studies 1 and 2, we need to consider other relevant respects in which the events across these three categories might differ. The high-frequency and low-frequency life script events were closely matched, in Berntsen and Rubin (2004), on the question of how many people, out of 100, would experience the event at least once in their lives asked $\left(M_{\text {High Frequency }}=\right.$ 91.32 people; $M_{\text {Low Frequency }}=89.76$ people). For the non-life-script events, we asked 20 Danish university students the same question of these events. The ratings were comparable to those for the high-frequency and low-frequency life script events, $M=88.52$ people. Again, these prevalence ratings also serve as a proxy for the perceived general plausibility of an event, in light 
of the strong association between prevalence and plausibility (Pezdek, Blandon-Gitlin, Lam, et al., 2006).

The three categories were also similar in their distributions of positive, negative, and neutral events. According to the ratings from Berntsen and Rubin (2004), the high-frequency category contained seven positive events (with mean ratings of $\geq .75$ on their Likert scale of -3 +3 ), two negative events (with mean ratings of $\leq-.75$ ), and one neutral event (with a mean rating of $>-.75<.75$ ), while, by the same criteria, the low-frequency category contained eight positive events, one negative event, and one neutral event. For the non-life-script events, we again asked 20 Danish university students to rate their emotional valence, using Berntsen and Rubin's Likert scale of $-3-+3$. Participants rated nine of them as positive, and one as negative.

Recall task. We employed essentially the same recall task as in Study 2, with the only difference being the exclusion of the remember/know judgements. The task was again administered on a computer screen, and, again, participants were instructed, initially, to recall the first specific event from the story that they could remember. They were advised, as in Study 2, as to what we meant by a specific event. For this event, they were asked to rate its emotional valence on the same Likert scale of 1 to 7 . Participants were then asked to recall the second event they could think of, and asked to rate its emotional valence, with this process repeated until participants indicated that they could not recall any more events.

Procedure. As in the preceding studies, Study 3 took place over three phases: (1) a reading phase, (2) a delay, and (3) a testing phase. In the reading phase, participants read the story on a computer screen. Each event from the story was presented as a single paragraph, and participants controlled their own pace through the story, being instructed to continue in the story 
once they had finished reading each paragraph. Participants were dismissed after reading the story, returning a week later for the testing phase, at which point they completed the recall task.

Coding of the recall task. As in Study 2, coding of the recall task focused on: (1) the proportion of correctly recalled events, and (2) the number of intrusions. In each case, we followed the same procedure as in Study 2. Once again, $50 \%$ of the recall tasks were dual-coded by two independent raters, and we again found high reliability across the two coders, with reliability ratings again exceeding .80 in both cases. The remaining recall tasks were coded by one rater.

Design. There was only one independent variable in Study 3, the frequency in the life script of the critical events in the story. This was a within-subjects variable, with three levels (high-frequency life script events, low-frequency life script events, and non-life-script events). As in Study 2, though the study's design did not explicitly probe for intrusions, we were still interested in whether the influence of the life script would be found therein.

\section{Results and Discussion}

In the following, we divide our results along three sets of discrete analyses, concerning, respectively: (1) correct recall, (2) intrusions, and (3) recalled emotional valence.

Correct recall. As in Study 2, we calculated the proportions of events recalled from each event category (e.g., high-frequency life script events). Descriptive statistics for these proportions are reported in Table 4. In an ANOVA with frequency in the life script as a within- 
subjects factor (high-frequency life script events vs. low-frequency life script events vs. non-lifescript events), we found a significant difference in the proportion of events recalled across these three categories, $F(2,58)=91.85, p<.001, n_{p}{ }^{2}=.76$. As Table 4 indicates, follow-up pairedsamples $t$-tests revealed the expected relation between frequency in the life script and recall, with high-frequency life script events recalled at higher rates than low-frequency life script events, $t(29)=8.23, p<.001, d=1.50$, which, in turn, were recalled at higher rates than non-life-script events, $t(29)=4.70, p<.001, d=.86$. The proportion of filler events recalled was $.53(S D=$ $.24)$.

Also as in Study 2, we calculated, individually for each participant, the Spearman rank correlation between the order in which events were recalled and the order in which they appeared in the story. We again collapsed across both critical and filler events. Participants again largely recalled events in the order in which they were presented in the story, with a mean correlation coefficient across participants of $.63(S D=.49)$, significantly greater than a correlation coefficient of $0, t(29)=6.97, p<.001, d=1.27$.

Intrusions. We first calculated, individually for each participant, the proportion of recalled events (including filler events from the story) which represented intrusions. We did this to attain an overall measure of the frequency of intrusions. Next, we coded each intrusion according to whether it represented a life script intrusion, or a non-life-script intrusion, that is, whether it represented one of the life script events from Berntsen and Rubin (2004). Lastly, from this coding we calculated, for each participant, the proportion of their total number of recalled events which represented each type of intrusion. 
Although the overall proportion of intrusions was still low in this study, the intrusions we did attain were predominantly of life script events. Correspondingly, there were significantly more life script intrusions than non-life-script intrusions $\left[M_{\text {Life Script Intrusions }}=.021(S D=.05)\right.$ to $\left.M_{\text {Non-Life-Script Intrusions }}=.003(S D=.01) ; t(29)=2.24, p=.033, d=.41\right]$.

Recalled emotional valence. In the absence of the schema-consistency manipulation, we could not probe for a pattern of emotional memory reconstruction, as we had in Study 2. However, we were interested in whether, of the events remembered in the recall task, recalled emotional valence varied across high-frequency life script events, low-frequency life script events, and non-life-script events. If this were the case, it may have undermined our claim that frequency in the life script drove the mnemonic distinctions across these three categories, as it would raise the prospect that recalled emotional valence of the remembered events was a factor. As it turned out, recalled emotional valence was not significantly different across the three event categories $\left[M_{\text {High-Frequency Life Script Events }}=5.18(S D=.64), M_{\text {Low-Frequency Life Script Events }}=5.35(S D=\right.$ $1.18)$, and $\left.M_{\text {Non-Life-Script Events }}=4.66(S D=.90) ; F(2,42)=1.83, p=.17\right]$, thereby providing no support for this possibility.

Discussion. In sum, in Study 3 we attained further evidence for the association between the frequency with which an event is cited as part of the life script and its accessibility in memory. Under conditions in which participants were presumably more reliant upon the life script than in Studies 1 and 2, we not only replicated the finding that high-frequency life script events are remembered better than low-frequency life script events, we also found that, in turn, low-frequency life-script events were remembered better than non-life-script events. Lastly, we 
found that outright intrusions disproportionately consisted of false recall for life script events, relative to non-life-script events.

\section{General Discussion}

\section{Primary Findings}

Across the three studies presented here, our main finding was that, in probing memory for a fictional life story, there was an association between an event's frequency in the life script and its accessibility in recognition and recall: High-frequency events were remembered better than low-frequency events (in all three studies, though there was only a trend to this effect in Study 2), which, in turn, were remembered better than non-life-script events (though we only tested this effect in Study 3). This effect was particularly pronounced in Study 3, where the inclusion of more critical events in the story left participants more reliant upon the life script schema in recalling it.

The relation we found between frequency in the life script and accessibility in recognition and recall supports, in a laboratory setting, Berntsen and Rubin's (2004) assertions, based on autobiographical memory data, that the life script heightens the mnemonic accessibility of events falling within it (see also Rubin \& Berntsen, 2003). The fact that we could not experimentally manipulate events' frequency in the life script leaves open the possibility that another factor common to high-frequency life script events, other than their frequency in the script, underlies their memorability. However, as we have noted throughout the paper, the events we employed across each event category differed neither in their estimated prevalence, nor (at least in Study 3) in their emotional valence. Similarly, in Study 3, in our analyses of recalled emotional valence for the events which participants had remembered in the recall task, there was no significant 
difference in recalled emotional valence across high-frequency life script events, low-frequency life script events, and non-life-script events.

Indeed, one noteworthy aspect of our findings is that our laboratory setting allowed us to create conditions which, generally speaking, left little room for alternative explanations of the association between events' frequency in the life script and their memorability. For instance, one might suspect that the general plausibility of each event served as a confound in relation to this set of findings, inasmuch as, in autobiographical memory, individuals are more likely to remember an event, or at least believe they experienced the event, if they consider it to be plausible (Hart \& Schooler, 2006; Mazzoni, Loftus, \& Kirsch, 2001; Pezdek, Blandon-Gitlin, \& Gabbay, 2006; Pezdek, Blandon-Gitlin, Lam, et al., 2006; Pezdek, Finger, \& Hodge, 1997; Scoboria, Mazzoni, Kirsch, \& Relyea, 2004).

However, as we have noted throughout the paper, the prevalence ratings collected by Berntsen and Rubin (2004) in relation to the life script events we employed in the current studies, as well as the prevalence ratings we collected ourselves for the non-life-script events employed in Study 3, effectively allowed us to disentangle the frequency of an event in the life script from its general plausibility. That is, as noted in the Introduction, in the memory construction literature, the perceived plausibility of an event is considered to be a function of its perceived frequency of occurrence (Pezdek, Blandon-Gitlin, Lam, et al., 2006). Therefore, we can rule out event plausibility as a confound in accounting for the mnemonic effects of event frequency, given that, again, the events we employed across each event category (i.e. highfrequency events, low-frequency events, and non-life-script events) differed only negligibly in their estimated prevalence. Furthermore, unlike in autobiographical memory, where many highfrequency life script events would also be expected to rate highly on such dimensions as 
This is an Accepted Manuscript of an article published by Taylor \& Francis in Memory, 22, 949-971 on $17^{\text {th }}$ December 2013, available online at: http://www.tandfonline.com/10.1080/09658211.2013.859269.

emotional intensity, personal importance, and rehearsal, this is unlikely to have been the case for the events in the bland fictional life story we employed.

One factor that may be related to frequency in the life script is an event's centrality in the script, as high-frequency events (e.g., having children and marriage) are likely to be considered more central to the life script than are low-frequency events (e.g., parents' death and first job). The number of citations of an event as a life script event may, in fact, be driven in part by centrality to the script; indeed, related findings by Galambos and Rips (1982) suggests this could be the case: In asking participants to judge whether a given episode was part of a given routine (e.g., going on vacation), they found that the centrality of an event to a routine was associated with the time it took to make such judgements. Therefore, inasmuch as frequency and centrality are likely to be highly related concepts, we would expect that highly central events would, likewise, be recognized and recalled at higher rates than less central events.

\section{Complementary Findings}

We also found varying degrees of evidence for three other discrete effects, which serve to complement our primary finding of the effect of frequency in the life script on recognition and recall: (1) Schema-inconsistent events were given remember judgements more often than schema-consistent events (in Study 2, with a trend to the same effect in Study 1); (2) where an event's emotional valence was inconsistent with the life script, memory for its valence was reconstructed according to the script (in Study 2); and (3) intrusions in recall were disproportionately for life script events (in Study 3, though there were not enough intrusions to conduct this analysis in Study 2, and we attained null results for false recognition in Study 1). To be sure, the findings regarding schema-consistency, which were confined to Studies 1 and 2, 
were attained in reference to a relatively small number of critical events on which we could conduct the relevant analyses. Nonetheless, the similar sets of findings we attained across the two studies indicates that our results are still highly reliable.

Taken together, and in combination with our primary finding concerning the effect of event frequency on recognition and recall, this array of results provides support for Berntsen and Rubin's claims that the cultural life script structures recall from autobiographical memory (Berntsen \& Rubin, 2004; Rubin \& Berntsen, 2003), by showing that the life script serves as a cognitive schema in its effect on memory and its phenomenological properties. Below, we briefly take up each of these secondary points.

Schema-consistency and remember/know judgements. Unlike frequency in the life script, which is a means of classifying events that is, by definition, unique to the life script, our schema-consistency manipulation was inspired by prior schema studies, in which researchers have generally classified items according to their consistency with the particular schema under investigation. They have typically found that schema-inconsistent items are remembered better than schema-consistent items, at least in recognition memory (Graesser et al., 1979; Lampinen et al., 2001; Neuschatz et al., 2002; Shapiro \& Fox, 2002). Similarly, researchers have also found that, when asked to make remember-know judgements, participants assign more remember judgements to schema-inconsistent items than to schema-consistent items (Lampinen al., 2000; Lampinen et al., 2001; Tuckey \& Brewer, 2003). Therefore, our finding that the latter effect extends to schema-inconsistent versus schema-consistent life script events establishes that the effect of schemata on the phenomenological properties of recollection holds for the life script as well. Just as, in other schemata, the greater distinctiveness of schema-inconsistent items renders 
it easier for individuals to reinstate the spatio-temporal context in which such items were initially encoded, this is likewise true of the life script schema.

Again, though this effect of schema-consistency on remember/know judgements reached statistical significance in Study 2, we only attained a trend to this effect in Study 1. Therefore, one should exercise caution in interpreting our results. However, we believe that, taken together, the results from these two studies strongly suggest that, just as with other schemata, an item's consistency with the life script schema affects remember/know judgements.

One respect in which our findings differed from those of prior schema studies was our failure to find that, apart from remember/know judgements, schema-inconsistent items were either recognized or recalled in higher proportions than schema-consistent items. As we noted, however, our schema-consistency manipulation was subtler than the manipulations typically employed in prior schema studies, inasmuch as we manipulated one of the salient characteristics of the relevant events (i.e., their emotional valence), as opposed to the events themselves. A manipulation of schema-consistency that involved manipulating the events themselves, such as by inserting inherently script-violating events into a life story, may yield an effect of schemaconsistency on memory accessibility.

Memory for emotional valence. As with the effect of frequency in the life script, our findings concerning memory for emotional valence are also specific to the life script schema. As such, they provide telling evidence for the influence of the life script on memory. One potential caveat concerning our findings here is that our evidence for the reconstruction of recalled valence for schema-inconsistent events was in comparison to norms collected from a separate sample, rather than prior ratings collected from the same sample. That is, we did not track, 
within-subjects, a shift in recalled valence for schema-inconsistent events. However, we opted for this between-subjects comparison to avoid the possibility of rehearsal effects, in that the participants from whom we drew the ratings of recalled emotional valence had not previously rated the emotional valence of the critical events in the story. Moreover, even in our betweensubjects comparison, the contrasting pattern in the difference between recalled valence and the norm ratings, across schema-consistent and schema-inconsistent events, serves as strong support for our claim that the life script partially governs recalled emotional valence of events falling under it.

The clustering of the ratings for the recalled emotional valence of schema-inconsistent events around the midpoint of the 7-point scale we employed (see Figure 2) raises another potential caveat: For these events, some participants may have simply selected the midpoint of the scale, rather than more actively reconstructed their emotional valence according to the life script. Even if this were the case, however, this finding would nonetheless represent an effect of the schema-consistency manipulation on recalled emotional valence, in that no such tendency was evident in recalled emotion for schema-consistent events. That is, it would suggest that, in the case of schema-inconsistent events, the discrepancy between the normative emotional valence of these events on the one hand, and their actual emotional valence as presented in the life story on the other, led participants to fall back on a response strategy (i.e., the selection of the midpoint of the scale) which they did not need to employ for schema-consistent events.

In either case, these findings complement recent research by Levine and colleagues, who have previously identified one source of reconstruction in memory for emotion, that individuals use their current emotional state as a guide in attempting to recall former emotional states (for a review, see Levine, Safer, \& Lench, 2006). Here, we have ascertained another reconstructive 
force in emotional memory. Moreover, similar to Levine and colleagues' demonstrations that the expected congruence between current and former emotional states leads to systematic distortions in emotional recall, our findings suggest that the influence of the life script schema produces a similar effect: When the actual emotional valence of events differs with the valence that would be expected based on the script, memory for their valence is subsequently distorted in the direction of the script.

Intrusions in recall. In interpreting our finding that, in Study 3, intrusions in recall were largely of life script events, it is helpful to bear in mind Brewer and Treyens' (1981) framework, reviewed in the Introduction, for the mechanisms underlying false memories. Brewer and Treyens view schematic false memories as reflecting the integration between semantic and episodic sources of knowledge. That is, if semantic and episodic sources become too closely integrated, then individuals are unable to distinguish between the two, and are liable to mistakenly draw upon semantic information in attempting to retrieve their episodic recollection. Intrusions, in that case, represent the inadvertent blending of semantic information into one's episodic memory.

Taken in this light, the predominance of life script events in participants' intrusions concerning the fictional life story is striking. That is, if we view intrusions as representing the inadvertent incorporation of semantic knowledge into one's episodic recollection, our results indicate that the life script is the primary source of semantic knowledge for what normally occurs in a life story.

To be sure, even where we attained this result - that is, in Study 3 - intrusions were still relatively infrequent. Therefore, though our findings suggest that most intrusions in memory for 
a fictional life story are driven by the life script, they indicate that such intrusions may still be relatively rare. However, one should bear in mind that, by some lights, the one-week retention interval we employed was minimal. Over a longer retention interval, as individuals come to rely more on their semantic knowledge and less on their episodic memory, the frequency of life script intrusions would likely increase.

\section{Limitations}

We should note, in particular, one limitation engendered in our design, specifically in Studies 2 and 3. Namely, we allowed participants to read through the story at their own pace in these two studies, without explicitly instructing them to only read each event once; this creates the possibility that participants may have read some events multiple times, while reading other events only once, and that these unequal reading times may have been responsible for the effects of either event frequency or schema-consistency. However, we consider this possibility to be unlikely: For differential reading times to underlie either set of effects, participants would have had to systematically spend more time reading either high-frequency events than low-frequency events, or schema-inconsistent events than schema-consistent events, and there is no reason to suspect this was the case. Furthermore, it is worth noting that we attained similar effects of event frequency and schema-consistency for recognition in Study 1, in which we controlled the pace at which participants read the story, suggesting that differential reading times was not responsible for either set of results. 
This is an Accepted Manuscript of an article published by Taylor \& Francis in Memory, 22, 949-971 on $17^{\text {th }}$ December 2013, available online at: http://www.tandfonline.com/10.1080/09658211.2013.859269.

\section{Conclusions}

Although we have extracted one primary finding and three complementary findings from the current investigation, each set of results contributes to the same consistent story: The cultural life script serves as a cognitive schema in how it structures memory and its phenomenological properties. As is clear from the literature we reviewed in the Introduction, humans possess numerous schemata, which partially govern a range of cognitive processes pertaining to the events, scenes, or people towards which they apply. The present results establish that, to these cognitive schemata, we must add the cultural life script. 


\section{References}

Anderson, R. C., \& Pichert, J. W. (1978). Recall of previously unrecallable information following a shift in perspective. Journal of Verbal Learning and Verbal Behavior, 17, $1-12$.

Bartlett, F. C. (1932). Remembering: A study in experimental and social psychology. Cambridge, UK: Cambridge University Press.

Bergman, E. T., \& Roediger, H. L. (1999). Can Bartlett's reproduction experiments be replicated? Memory \& Cognition, 27, 937-947.

Berntsen, D., \& Rubin, D. C. (2004). Cultural life scripts structure recall from autobiographical memory. Memory \& Cognition, 32, 427-442.

Bower, G., Black, J., \& Turner, T. J. (1979). Scripts in text comprehension and memory. Cognitive Psychology, 11, 177-220.

Brewer, W. F., \& Treyens, J. C. (1981). Role of schemata in memory for places. Cognitive Psychology, 13, 207-230.

Coleman, J. T., \& Belli, R. F. (2009). Does item typicality affect memory for life script events? Poster presented at the 50th annual meeting of the Psychonomic Society, Boston, MA.

Elischberger, H.B. (2005). The effects of prior knowledge on children's memory and suggestibility. Journal of Experimental Child Psychology, 92, 247-275

Erdoğan, A., Baran, B., Avlar, B., Cağlar, T. A., \& Tekcan, A. İ. (2008). On the persistence of positive events in life scripts. Applied Cognitive Psychology, 22, 95-112.

Galambos, J. A., \& Rips, L. J. (1982). Memory for routines. Journal of Verbal Learning and Verbal Behavior, 21, 260-281. 
García-Bajos, E., \& Migueles, M. (2003). False memories for script actions in a mugging account. European Journal of Cognitive Psychology, 15, 195-208.

Graesser, A. C., Gordon, S. E., \& Sawyer, J. D. (1979). Recognition memory for typical and atypical actions in scripted activities: Tests of a script pointer + tag hypothesis. Journal of Verbal Learning and Verbal Behavior, 18, 319-332.

Graesser, A. C., Woll, S. B., Kowalksi, D. J., \& Smith, D. A. (1980). Memory for typical and atypical actions in scripted activities. Journal of Experimental Psychology: Human Learning and Memory, 6, 503-515.

Habermas, T. (2007). How to tell a life: The development of the cultural concept of biography. Journal of Cognition and Development, 8, 1-31.

Haque, S., \& Hasking, P. A. (2010). Life scripts for emotionally charged autobiographical memories: A cultural explanation of the reminiscence bump. Memory, 18, 712-729.

Hart, R. E., \& Schooler, J. W. (2006). Increasing belief in the experience of an invasive procedure that never happened: The role of plausibility and schematicity. Applied Cognitive Psychology, 20, 661-669.

Holst, V. F., \& Pezdek, K. (1992). Scripts for typical crimes and their effects on memory for eyewitness testimony. Applied Cognitive Psychology, 6, 573-587.

Hunt, R. R. (2006). The concept of distinctiveness in memory research. In R. R. Hunt \& J. B. Worthen (Eds.), Distinctiveness and memory (pp. 3-25). New York, NY: Oxford University Press.

Janssen, S. M. J., \& Rubin, D. C. (2011). Age effects in cultural life scripts. Applied Cognitive Psychology, 25, 291-298. 
Kleider, H. M., Goldinger, S.D., Knuycky, L. (2008). Stereotypes influence false memories for imagined events. Memory, 16, 97-114.

Kleider, H. M., Pezdek, K., Goldinger, S. D., \& Kirk, A. (2008). Schema-driven source misattribution errors: Remembering the expected from a witnessed event. Applied Cognitive Psychology, 22, 1-20.

Lampinen, J. M., Copeland, S. M., \& Neushatz, J. S. (2001). Recollection of things schematic: Room schemas revisited. Journal of Experimental Psychology: Learning, Memory, \& Cognition, 27, 1211-1222

Lampinen, J. M., Faries, J. M., Neuschatz, J. S., \& Toglia, M. P. (2000). Recollections of things schematic: The influence of scripts on recollective experience. Applied Cognitive Psychology, 14, 543-554.

Levine, L. J., Safer, M. A., \& Lench, H. C. (2006). Remembering and misremembering emotions. In L. J. Sanna \& E. C. Chang (Eds.), Judgements over time: The interplay of thoughts, feelings and behaviors (pp. 271-290). New York, NY: Oxford University Press.

List, J. A. (1986). Age and schematic differences in the reliability of eyewitness testimony. Developmental Psychology, 22, 50-57.

Mandler, J. M., \& Johnson, N. S. (1977). Remembrance of things parsed: Story structure and recall. Cognitive Psychology, 9, 111-151.

Mazzoni, G. A. L., Loftus, E. F., \& Kirsch, I. (2001). Changing beliefs about implausible autobiographical events: A little plausibility goes a long way. Journal of Experimental Psychology: Applied, 7, 51-59.

Neisser, U. (1976). Cognition and reality. San Francisco, CA: W. H. Freeman. 
Nemeth, R. J., \& Belli, R. F. (2006). The influence of schematic knowledge on contradictory versus additive misinformation: False memory for typical and atypical items. Applied Cognitive Psychology, 20, 563-573.

Neuschatz, J. S., Lampinen, J. M., Preston, E. L., Hawkins, E. R., \& Toglia, M. P. (2002). The effect of memory schemata on memory and the phenomenological experience of naturalistic situations. Applied Cognitive Psychology, 16, 687-708.

Ornstein, P. A., Merritt K. A., Baker-Ward, L., Furtado, E., Gordon, B. N, \& Principe, G. C. (1998). Children's knowledge, expectation, and long-term retention. Applied Cognitive Psychology, 12, 387-405.

Otgaar, H., Candel, I., Scoboria, A., \& Merckelbach, H. (2010). Script knowledge enhances the development of children's false memories. Acta Psychologica, 133, 57-63.

Otgaar, H., Smeeets, T., \& Peters, M. (2012). Children's implanted false memories and additional script knowledge. Applied Cognitive Psychology, 26, 709-715.

Pezdek, K., Blandon-Gitlin, I., \& Gabbay, P. (2006). Imagination and memory: Does imagining implausible events lead to false autobiographical memories? Psychonomic Bulletin \& Review, 13, 764-769.

Pezdek, K., Blandon-Gitlin, I., Lam, S., Hart, R. E., \& Schooler, J.W. (2006). Is knowing believing? The role of event plausibility and background knowledge in planting false beliefs about the personal past. Memory \& Cognition, 34, 1628-1635.

Pezdek, K., Finger, K., \& Hodge, D. (1997). Planting false childhood memories: The role of event plausibility. Psychological Science, 8, 437-441. 
Pezdek, K., Whetstone, T., Reynolds, K., Askari, N., \& Dougherty, T. (1989). Memory for realworld scenes: The role of consistency with schema expectation. Journal of Experimental Psychology: Learning, Memory, and Cognition, 15, 587-595.

Rajaram, S. (1993). Remembering and knowing: Two means of access to the personal past. Memory \& Cognition, 21, 89-102.

Roediger, H. L., Meade, M. L., \& Bergman, E. T. (2001). Social contagion of memory. Psychonomic Bulletin \& Review, 8, 365-371.

Rubin, D. C., \& Berntsen, D. (2003). Life scripts help to maintain autobiographical memories of highly positive, but not highly negative, events. Memory \& Cognition, 31, 1-14.

Rubin, D. C., Berntsen, D., \& Hutson, M. (2009). The normative and the personal life: Individual differences in life scripts and life story events among USA and Danish undergraduates. Memory, 17, 54-68.

Rubin, D. C., \& Schulkind, M. D. (1997). The distribution of autobiographical memories across the lifespan. Memory \& Cognition, 25, 859-866.

Scoboria, A., Mazzoni, G., Kirsch, I., \& Relyea, M. (2004). Plausibility and belief in autobiographical memory. Applied Cognitive Psychology, 18, 791-807.

Shapiro, M. A., \& Fox, J. R. (2002). The role of typical and atypical events in story memory. Human Communication Research, 28, 109-135.

Sherman, J. W., \& Bessenhoff, G. R. (1999). Stereotypes as source-monitoring cues. Psychological Science, 10, 106-110.

Smith, D. A., \& Graesser, A. C. (1981). Memory for actions in scripted activities as a function of typicality, retention interval, and retrieval task. Memory \& Cognition, 9, 550-559. 
Smith, V. L., \& Studebaker, C. A. (1996). What do you expect: The influence of people's prior knowledge of crime categories on fact-finding. Law and Human Behavior, 20, 517-532.

Sulin, R. A., \& Doolin, D. J. (1974). Intrusion of a thematic idea in retention of prose. Journal of Experimental Psychology, 103, 255-262.

Tuckey, M. R., \& Brewer, N. (2003). The influence of schemas, stimulus ambiguity, and interview schedule on eyewitness memory over time. Journal of Experimental Psychology: Applied, 9, 101-118.

Tulving, E. (1985). Memory and consciousness. Canadian Psychologist, 26, 1-12.

von Restorff, H. (1933). Über die Wirkung von Bereichsbildungen im Spurenfeld [The effects of field formation in the trace field]. Psychologie Forschung, 18, 299-342. 


\section{Appendix}

\section{Sample Story Used in Studies 1 and 2}

Anna was born in a small town outside of Copenhagen. Her mother was a nurse and her father was an engineer. She had an extremely enjoyable childhood, and her favorite activities were drawing and playing outside. She also had a very good relationship with her parents.

When Anna was five, she developed her first friendship, with a girl named Clara. Clara was the daughter of friends of her parents, so they had many play dates together, and they liked each other a great deal. They often did finger painting and played with dolls together.

Anna started attending school at the age of 6. She enjoyed school, as she was an excellent student and had many friends. Her favorite subjects were arithmetic and music. She continued to enjoy school all the way through high school.

Although Anna enjoyed her life at home, she was also very excited when she graduated from high school, at the age of 19 , and had the opportunity to experience living on her own. She left home and moved to Copenhagen. In Copenhagen, she got an apartment with a few friends of hers. They had a great time together.

To this point, Anna had never been on a long trip to another continent. She was curious to see other parts of the world, and she had always been particularly fascinated by Japanese culture and food. Therefore, she and her roommate, Kathrine, planned a trip to Tokyo. However, although 
Anna had been very excited for her first long trip, it ended up being an awful experience. Anna and Kathrine fought constantly, over things like which hotels to stay in and which restaurants to eat at. In particular, Anna always thought that Kathrine's choices of lodgings and food were far too expensive for their budget. They fought so much that the trip ruined their friendship; when they got back to Denmark, they scarcely spoke to each other again.

Upon returning to Denmark, Anna realized it was time that she got serious about her future. She applied to the University of Copenhagen, to study economics. She was accepted into the program, and looked forward to beginning her studies that fall. At the university, she quickly found that she had a great interest in economics, as well as an aptitude for the subject. She threw herself into her studies and enjoyed them very much.

In her second year, she met a fellow economics student named Rasmus. She and Rasmus were in a study group together, along with several other students. They gradually developed a serious relationship, which they continued through the rest of their time as students.

After graduating, Rasmus asked Anna to marry him. She was thrilled to get married to Rasmus, and they had a beautiful wedding. After the wedding, they stayed in Copenhagen and got an apartment together.

Shortly after the wedding, Anna also got her first serious job, as a research analyst at an advertising agency. Anna had been reluctant to get a job, because she'd wanted to have a more traditional marriage and be a housewife. However, she and Rasmus needed two incomes, so she 
felt she had to go to work. She liked her job well enough, but she couldn't help but feel that she would rather not have to be working in the first place.

Before they'd gotten married, Anna and Rasmus had decided they wanted to start having children soon. So they were both very happy when Anna got pregnant a few months after their wedding. They ended up having a boy, and they named him Noah.

Unfortunately, however, having a child ended up putting a strain on Anna and Rasmus' marriage, as they had many disagreements about how to raise their son. Rasmus became increasingly withdrawn, and, eventually, he said he wanted to get a divorce. Anna had been hopeful that their marriage could be improved, and she was concerned about the effect the divorce would have on their son. However, Rasmus was firm that he thought a divorce was their only option at that point, and, therefore, they got divorced. They parted on very poor terms, and rarely spoke thereafter except for matters relating to their son.

After the divorce, Noah primarily stayed with Anna. Her parents moved to Copenhagen in order to help raise Noah as she went back to work. As the years went by, Noah grew older, going to high school and then moving into his own apartment and attending university, also at the University of Copenhagen.

As Noah was starting at the university, both of Anna's parents became quite ill - Anna's father was diagnosed with lung cancer, and her mother developed coronary artery disease. They both died shortly thereafter, as her father died soon after the lung cancer diagnosis, and, several weeks 
later, Anna's mother had a heart attack and died as well. Anna was quite distraught, as she had been close to her parents.

Meanwhile, Anna's son, Noah, had developed a serious relationship with a young woman at the university, named Rikke. They became quite close, and they got married soon after they graduated from the university. Anna was excited about her son's marriage, especially since it opened the possibility of Noah's having children of her own, as Anna very much wanted to be a grandmother.

Fortunately, Rikke got pregnant soon after she and Noah were married. She gave birth to a daughter, and Anna was thrilled to be a grandmother. She babysat her granddaughter twice a week while Rikke and Noah were at work. She loved babysitting her granddaughter, and had some of the happiest and most fulfilling times of her life doing so. Anna continued to be quite close to her granddaughter, even as she grew up, and, eventually, moved out of her parents' home and started attending university herself.

A couple of years after her granddaughter had begun university, Anna suddenly had a stroke. Although she initially survived, she was left in severely diminished physical condition. Noah and Rikke had to spend a lot of time visiting Anna in the hospital and taking care of her, and Anna felt like she had become a burden to her family.

At this point, Anna was an old woman of 78 years old, and she felt like she had accomplished everything she wanted to in life. Therefore, she was actually relieved when, as a complication of 
This is an Accepted Manuscript of an article published by Taylor \& Francis in Memory, 22, 949-971 on $17^{\text {th }}$ December 2013, available online at: http://www.tandfonline.com/10.1080/09658211.2013.859269.

the stroke, she developed a potentially fatal case of pneumonia. She refused further treatment and asked to be admitted to a hospice instead. She died there a month later, surrounded by her family and at peace with her life. 
This is an Accepted Manuscript of an article published by Taylor \& Francis in Memory, 22, 949-971 on $17^{\text {th }}$ December 2013, available online at: http://www.tandfonline.com/10.1080/09658211.2013.859269.

Table 1

Critical Events in Studies 1 and 2

\begin{tabular}{ccc}
\hline Event Category & Event & Citations in the Danish Life \\
& & Script (from Berntsen \& \\
& & Rubin, 2004) \\
High-Frequency & Having Children & 93 \\
& Marriage & 77 \\
Cow-Frequency & College & 56 \\
& Parents' Death & 24 \\
& First Job & 22 \\
Own Death & 12 \\
Divorce & 12 \\
Grandchildren & 11 \\
Long Trip & 10 \\
\hline
\end{tabular}

Note. For each event, citations represent the number of respondents, out of the 103 in Berntsen and Rubin's (2004) sample, who cited it as a life script event. Participants were asked to generate seven events in total. 
This is an Accepted Manuscript of an article published by Taylor \& Francis in Memory, 22, 949-971 on $17^{\text {th }}$ December 2013, available online at: http://www.tandfonline.com/10.1080/09658211.2013.859269.

\section{Table 2}

Mean Proportions of Events Recalled and Remember Judgements, Study 2

\begin{tabular}{ccccccc}
\hline \multirow{2}{*}{ Measure } & \multicolumn{3}{c}{ Schema-Consistency } & \multicolumn{3}{c}{ Event Frequency } \\
\cline { 2 - 7 } & Schema- & Schema- & $t$-value & High- & Low- & $t$-value \\
& Consistent & Inconsistent & & Frequency & Frequency \\
\hline Events & $.72(.19)$ & $.76(.30)$ & .63 & $.81(.22)$ & $.71(.20)$ & $1.86+$ \\
Recalled & & & & & & \\
Remember & $.66(.36)$ & $.86(.22)$ & $2.45^{*}$ & $.67(.35)$ & $.73(.35)$ & 1.15 \\
Judgements & & & & & & \\
\hline
\end{tabular}

$+p<.10 ; * p<.05$

Note. Standard deviations are in parenthesis. Proportions of remember judgements are drawn only from participants who recalled more than one event from the relevant event category (e.g., schema-consistent events; in all cases, $n \geq 19)$. 


\section{Table 3}

Critical Events in Study 3

Citations in the Danish Life

Event Category $\quad$ Event $\quad$ Script (from Berntsen and

Rubin, 2004)

\begin{tabular}{|c|c|c|}
\hline \multirow[t]{10}{*}{ High-Frequency Life Script } & Having Children & 93 \\
\hline & Marriage & 77 \\
\hline & Begin School & 68 \\
\hline & College & 56 \\
\hline & Fall in Love & 52 \\
\hline & Others' Death & 32 \\
\hline & Retirement & 31 \\
\hline & Leave Home & 26 \\
\hline & Parents' Death & 24 \\
\hline & First Job & 22 \\
\hline \multirow[t]{7}{*}{ Low-Frequency Life Script } & First Friend & 11 \\
\hline & Puberty & 11 \\
\hline & Grandchildren & 11 \\
\hline & Begin Walking & 9 \\
\hline & First Sexual Experience & 7 \\
\hline & Begin Talking & 6 \\
\hline & Confirmation & 6 \\
\hline
\end{tabular}


This is an Accepted Manuscript of an article published by Taylor \& Francis in Memory, 22, 949-971 on $17^{\text {th }}$

December 2013, available online at: http://www.tandfonline.com/10.1080/09658211.2013.859269.

\begin{tabular}{ccc}
\hline & Empty Nest & 4 \\
Low-Frequency Life Script & Baptism & 4 \\
(cont'd.) & Earn First Money & 4 \\
Non-Life-Script & Birth & N/A \\
& Read First Book & N/A \\
Learn to Swim & N/A \\
Learn to Ride a Bike & N/A \\
& First Drink of Alcohol & N/A \\
18 & N/A Birthday Party & N/A \\
Driver's License & N/A \\
Charter Vacation & N/A \\
Menopause & N/A \\
\hline
\end{tabular}

Note. For each event, citations represent the number of respondents, out of the 103 in Berntsen and Rubin's (2004) sample, who cited it as a life script event. Participants were asked to generate seven events in total. 
This is an Accepted Manuscript of an article published by Taylor \& Francis in Memory, 22, 949-971 on $17^{\text {th }}$

December 2013, available online at: http://www.tandfonline.com/10.1080/09658211.2013.859269.

Table 4

Mean Proportions of Events Recalled, Study 3

\begin{tabular}{ccc}
\hline High-Frequency & Low-Frequency & Non-Life-Script \\
\hline $.54^{\mathrm{a}}(.16)$ & $.25^{\mathrm{b}}(.12)$ & $.13^{\mathrm{c}}(.11)$ \\
\hline
\end{tabular}

Note. Standard deviations are in parenthesis. Means with different superscripts are significantly different from each other at a $p$ value of $<.001$. 


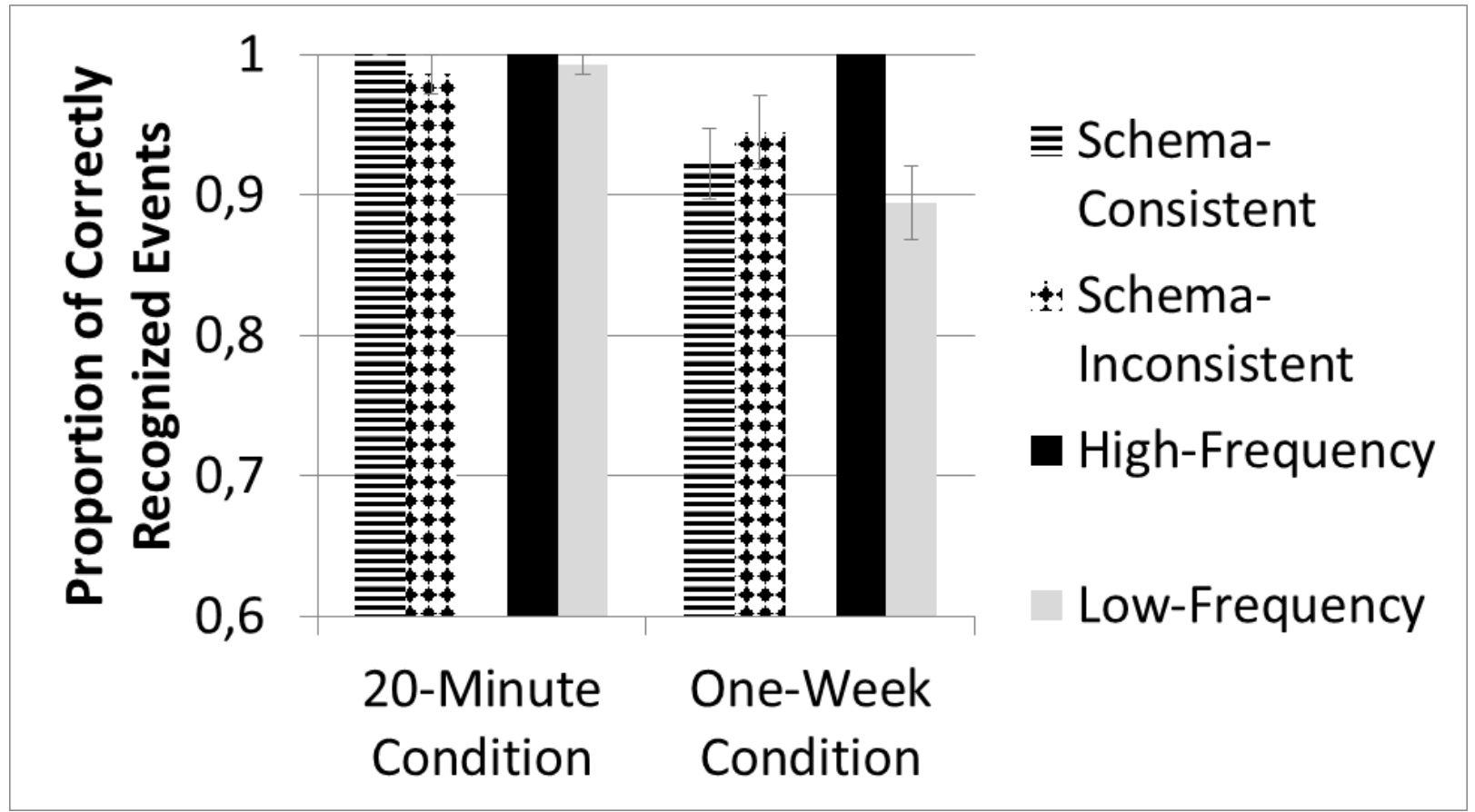

Figure 1a. Mean proportions of correctly recognized events, Study 1. Error bars are +/one SE. 


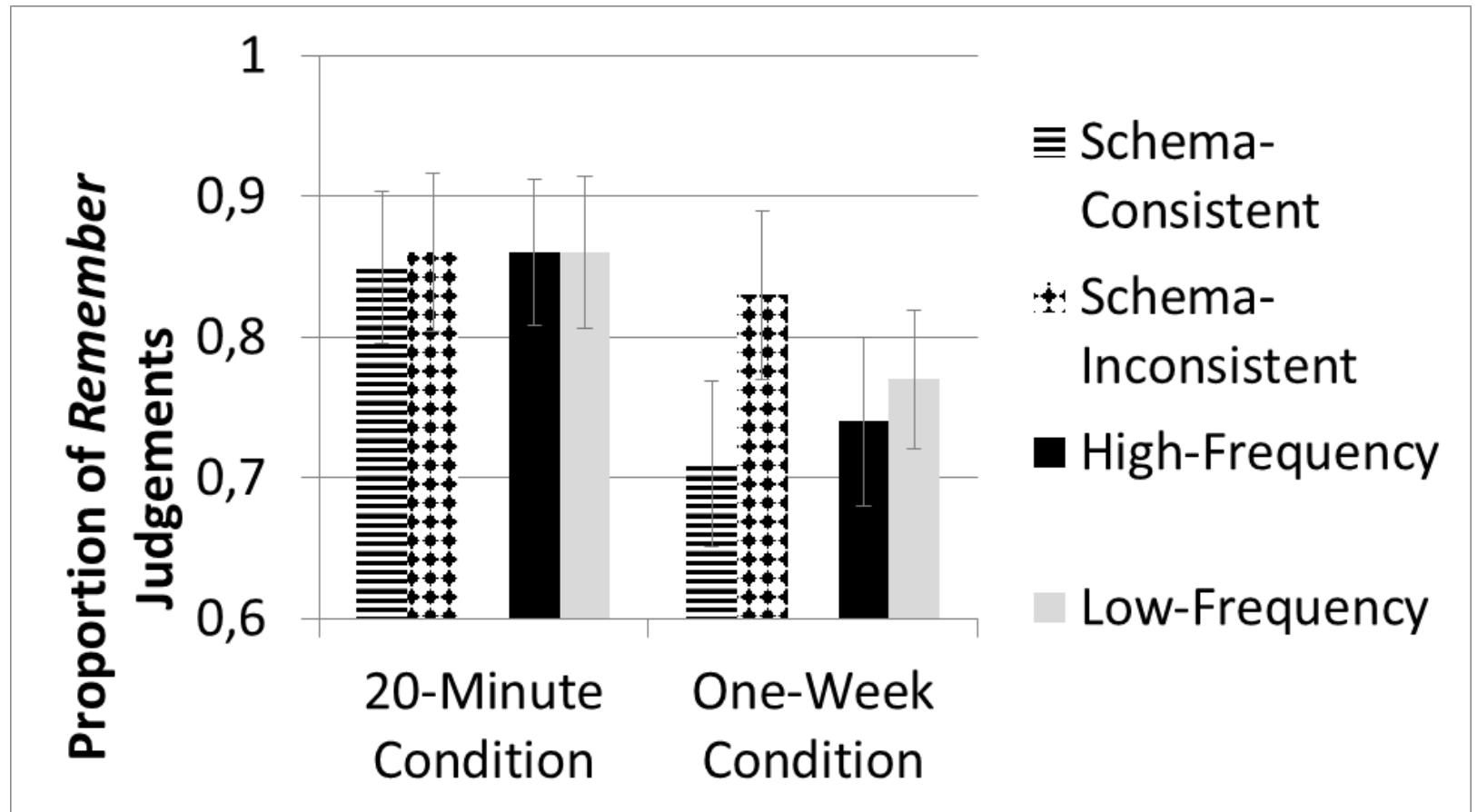

Figure $1 b$. Mean proportions of remember judgements, Study 1. Error bars are +/one SE. 


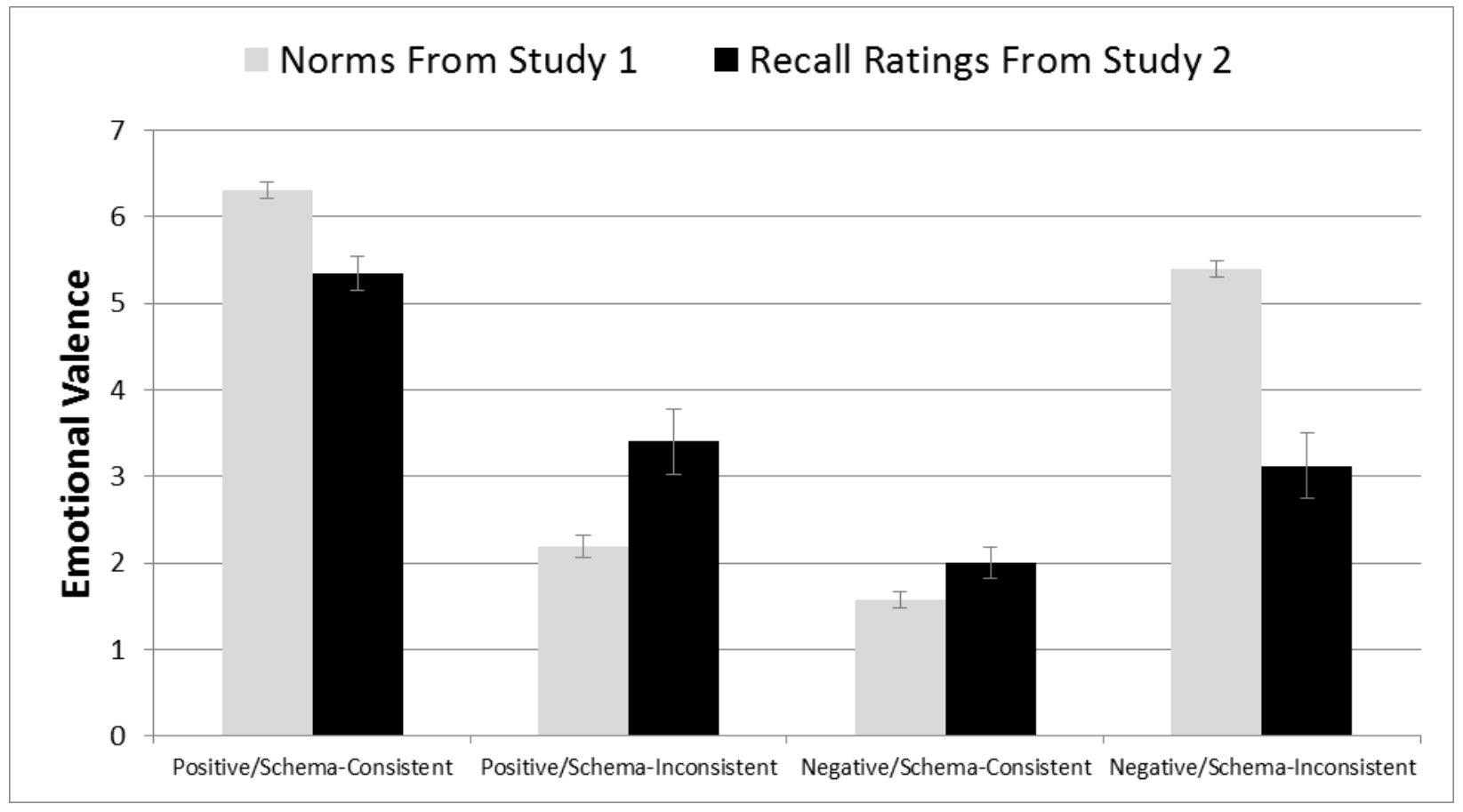

Figure 2. Mean ratings of norms of emotional valence ratings (from Study 1), and recalled emotional valence ratings (from Study 2). The ratings are collapsed across all positive schema-consistent events, positive schema-inconsistent events, negative schema-consistent events, and negative schema-inconsistent events. Error bars are +/- one SE. 